Abstracta Iranica Abstanica

Revue bibliographique pour le domaine irano-aryen

Volume 27 | 2006

Comptes rendus des publications de 2004

\title{
Pashtun Tales from the Pakistan-Afghan Frontier. London, Saqi Books, 2003, 379 p.
}

\section{Daniel Septfonds}

\section{(2) OpenEdition}

1 Journals

\section{Édition électronique}

URL : http://journals.openedition.org/abstractairanica/6536

DOI : 10.4000/abstractairanica.6536

ISSN : 1961-960X

Éditeur :

CNRS (UMR 7528 Mondes iraniens et indiens), Éditions de l'IFRI

\section{Édition imprimée}

Date de publication : 15 mai 2006

ISSN : 0240-8910

\section{Référence électronique}

Daniel Septfonds, «Pashtun Tales from the Pakistan-Afghan Frontier. London, Saqi Books, 2003, 379 p. », Abstracta Iranica [En ligne], Volume 27 | 2006, document 331, mis en ligne le 02 janvier 2007 , consulté le 25 septembre 2020. URL : http://journals.openedition.org/abstractairanica/6536 ; DOI : https://doi.org/10.4000/abstractairanica.6536

Ce document a été généré automatiquement le 25 septembre 2020.

Tous droits réservés 


\title{
Pashtun Tales from the Pakistan- Afghan Frontier. London, Saqi Books, 2003, 379 p.
}

\author{
Daniel Septfonds
}

1 Cet ouvrage est semble-t-il basé sur la parole presque exclusive d'un pashtoune de la N.W.F.P - pashtoune de la tribu Mohmand «Saed Khan Bâbâ ». On tient là, en quelque sorte, le répertoire - ou partie du répertoire - d'un conteur. [On aimerait en savoir plus : "I would like to thank Saed Khan Baba for relating most of the stories in this collection... " , p. 19]. L'ensemble a été traduit «oralement» en ourdou (p.20) pour l'A. [Aisha Ahmed] qui nous en donne une version anglaise.

2 Les contes eux-mêmes sont présentés de façon thématique : I. Wit and Intelligence (1-6), II. Virtues and Vices (7-10), III. Miracles and Magic (11-17), IV. Courtship and Infidelity (18-23), V. Epic and Romance (24-28), VI. Comedy and Farce (29-35).

3 L'ouvrage est agrémenté de 21 reproductions couleurs de scènes liées à l'histoire de l'Afghanistan. Celles-ci sont insérées au fil des chapitres: Table des matières (pp. 7-8), table des illustrations (pp. 8-9) - préface (pp. 11-20), 35 contes (pp. 21-320), analyse folklorique (pp. 321-354), notes (pp. 355-359) [classées par contes], glossaire (pp. 360-365), bibliographie (pp. 366-370), index des contes-types (pp. 371-372), index des motifs (pp. 373-379).

4 L'analyse folklorique est documentée. Les liens avec les versions des deux plus célèbres recueils de contes pashto (Malyon, F.H. 1980 [dans la bibliographie, édition de 1913], Pustu Folk Stories, IFH, Islamabad et Thorburn, S.S., 1978 [dans la bibliographie, édition de 1876], Bannu or our Afghan Frontier, Lahore) sont systématiquement indiqués.

Un regret cependant, l'index des contes-types n'est pas fiable: on peut se demander pourquoi le conte $n^{\circ} 19$ «The Prince and the Fakir » et le conte n' 25 "The King's Dream », par exemple, apparaissent comme contes-types AT 310 «The Maiden in the Tower » [Le n 19 est classé comme AT 1359 dans l'analyse folklorique et le n²5 n'est pas classé] - ce qu'ils ne sont en aucun cas. L'A. semble alors oublier qu'un épisode et encore moins un motif ne permettent d'indexer un conte. 
6 Un dernier point, il est difficile de savoir quelle est la contribution exacte de chacun des auteurs : «I am grateful to Dr Roger Boase for editing the text and compiling the notes and glossary... », p. 20 (?) - ce qui n'enlève rien à l'intérêt de l'ouvrage.

INDEX

Thèmes : 11.2. Littérature pashto et dari (Afghanistan)

\section{AUTEURS}

DANIEL SEPTFONDS

CNRS - Paris 